\section{Air recovery assessment on high-pressure pneumatic systems}

\author{
José A Trujillo, Pedro J Gamez-Montero \\ and Esteban Codina Maciàv
}

Proc IMechE Part C:

$J$ Mechanical Engineering Science

$0(0) \mathrm{I}-12$

(C) IMechE 2016

Reprints and permissions:

sagepub.co.uk/journalsPermissions.nav DOI: 10.1 I77/09544062। 6645823

pic.sagepub.com

\begin{abstract}
A computational simulation and experimental work of the fluid flow through the pneumatic circuit used in a stretch blow moulding machine is presented in this paper. The computer code is built around a zero-dimensional thermodynamic model for the air blowing and recycling containers together with a non-linear time-variant deterministic model for the pneumatic three stations single acting valve manifold, which, in turn, is linked to a quasi-one-dimensional unsteady flow model for the interconnecting pipes. The flow through the pipes accounts for viscous friction, heat transfer, cross-sectional area variation, and entropy variation. Two different solving methods are applied: the method of characteristics and the HLL Riemann first-order scheme. The numerical model allows prediction of the air blowing process and, more significantly, permits determination of the recycling rate at each operating cycle. A simplified experimental set-up of the industrial process was designed, and the pressure and temperature were adequately monitored. Predictions of the blowing process for various configurations proved to be in good agreement with the measured results. In addition, a novel design of a valve manifold intended for the polyethylene terephthalate (PET) plastic bottle manufacturing industry is also presented. [AQ1]
\end{abstract}

\title{
Keywords
}

Air recycling system, energy assessment, air blow moulding manufacturing process, pneumatic valve manifold

Date received: 6 November 20I5; accepted: 10 March 2016

\section{Introduction}

Despite the many contributions linked to energy conservation in pneumatic systems, no publications report the efficiency on high-pressure pneumatic applications. [AQ2]In order to bring some light to this issue, it is crucial to get into the patents published during the last 20 years. Amongst various industrial applications that require high-pressure air, polyethylene terephthalate (PET) stretch blow moulding machine manufacturers have contributed significantly to enhancing energy efficiency in that specific field of pneumatic systems.

In 1981 Air Products and Chemicals Inc. ${ }^{1}$ published a patent related to a process for the production of blow moulded articles in which the blowing gas was recovered and treated to be used in subsequent moulding operations. A year later Robert Bosch $\mathrm{GmbH}$ suggested recovering the compressed air used in the moulding operation to feed other pneumatic applications. A similar proposal was provided by The Continental Group Inc. ${ }^{2}$ in 1984, which was subsequently taken as a reference by other blow moulding bottle manufacturers. In 1995 Krupp Corpoplast Maschinenbau $\mathrm{GmbH}^{3,4}$ presented an invention that recovered part of the air used for moulding a container made of thermoplastic material. The highpressure blowing air was supplied to the low-pressure air supply during a transitional phase by employing a reversing mechanism. An invention that has been cited by several blowing machine manufacturers is the patent of Procontrol AG (1996), ${ }^{5}$ which proposed to produce the high-pressure air adiabatically while the low-pressure air was generated isothermically, thus enabling the entire blowing process to be carried out with the smallest possible amount of energy. Over the same period and based on the same principle, A.K. Tech Lab Inc. (1997) ${ }^{6}$ proposed recovering the exhaust air into a tank that later supplied air to operate secondary pneumatic circuits. In order to compensate for the difference between the recovered air and that consumed by the installation, a compressor

LABSON, Campus Terrassa, UPC, Terrassa, Barcelona, Spain

\section{Corresponding author:}

José A Trujillo, Escuela Tcnica Superior de Ingenieras Industrial y Aeronutica de Terrassa, Campus de Terrassa, Edificio TR5, C/ Colom, II Terrassa, 08222 Spain. Email: jose.trujillo@ast.es 


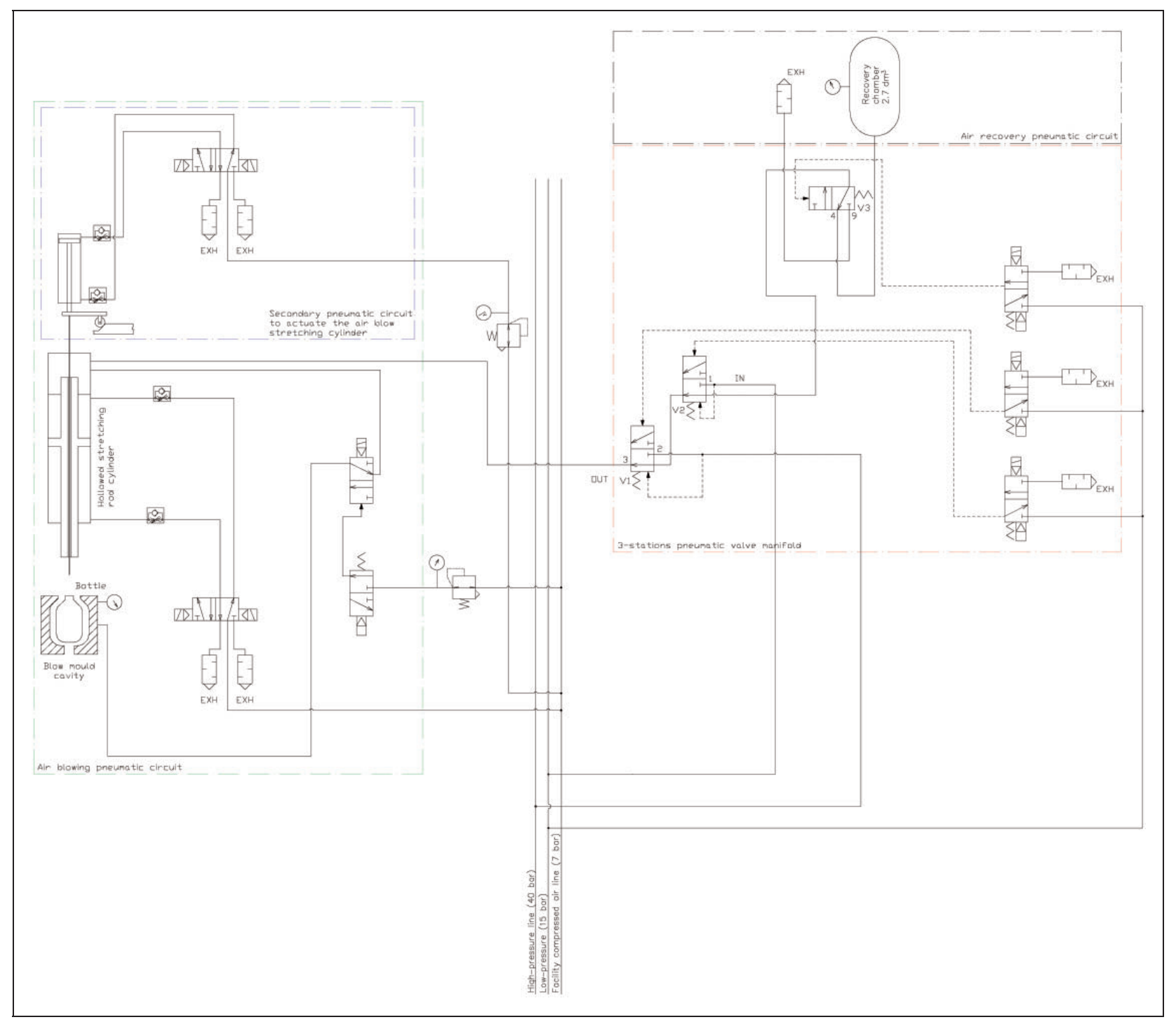

Figure I. [AQ30]Single station PET bottle production pneumatic scheme with air recovery system. [AQ5]

provided sufficient air to balance the pressure in the tank. Also, the proposal of Asahi Kasei Kogoyo Kabushiki Kaisha (1993) ${ }^{7}$ must be taken into account, which added a recovery container from which the compressed gas could be aspirated by a multistage compressor. In 2003 Technoplan $^{8}$ published an invention which targeted the optimization of the above-mentioned methods. A relevant improvement was the fact that the recovered gas (17 bar) was expanded before being used in the low-pressure air phase, which meant that it did not have influence on the low-pressure air at the time of its use. On the other hand, several proposals were given to re-use the recovered air, such as actuating the preform-stretching rams, actuating consumables of the packaging-production machine, or even returning the recycled gas to the compressed air network. The method allowed around $20 \%$ to $45 \%$ of air recovery and a reduction of electrical power consumption of $15 \%$ to $45 \%$.

[AQ3]Based on the existing state of the art it may be concluded that even though numerous attempts have been made to improve the efficiency of air blowing pneumatic systems, there are no previous publications which focused specifically on analysing the complexity of this particular industrial field. Therefore, this investigation aims to determine the main constraints that limit the efficiency of a blow moulding plastic PET bottle pneumatic circuit with the help of a computational model which is able to predict the maximum amount of recycled air that may be ensured at each operating cycle. Moreover, this tool will not only contribute to assessing the efficiency of the air blowing machine but will also allow redesigning of the regpneumatic lay-out to minimize the energy losses. ${ }^{9}$

\section{Mathematical model of the air blow moulding pneumatic system [AQ4]}

Due to the complexity of the air blow moulding machine, the pneumatic circuit has been reduced to the pneumatic scheme depicted in Figure 1, resulting 
in three individual submodels, which are represented by the fluid flow through the pipes, the charging and discharging process from/to the vessels and the fluid dynamics inside the valve manifold. The valve manifold is supplied with two different pressures, and a special cylinder is responsible for providing compressed air to the plastic preform through a hollowed stretching rod. From the patents mentioned in the previous section we learned that once the plastic bottle is produced, the air inside the container is partially recycled while the remaining fluid is exhausted to the atmosphere once the air level inside the recycling chamber reaches a certain pressure. It must be pointed out that the main scope of this study does not take into account the deformation of the preform during the blowing process, but the amount of air that is needed to produce the bottle. As a matter of fact the pressure characteristics inside the mould will behave slightly differently in a real blow moulding machine. On the other hand, for the sake of simplicity the simulation will omit the components located before the valve manifold, such as the filter and pressure regulator.

The recycling stage always takes place after closing $V_{1}$ (refer to Figure 1). At this point the air flows through the pipe connecting the cavity chamber and the manifold, and circulates through the valve manifold until it reaches the recycling chamber. At a certain stage, the air in the recycling chamber equalizes the pressure in the cavity chamber, being the point when the recycling process ends, and the remaining air in the cavity chamber is released to the atmosphere. As a matter of fact, the use of an additional recycling process may be also considered at this point, however, a different concept design of the valve manifold should be used. It must be noted that the amount of energy available in the cavity chamber drops as the pressure decreases so an additional recycling stage should be considered.

\section{Mathematical model at the pipes}

The flow through the pipes connecting the different units has been considered quasi-one-dimensional and the methods implemented in order to determine the characteristics of the fluid flow have been the method of characteristics (MOC) $)^{10,11}$ and the HLL Riemann solver $^{12-14}$ respectively. [AQ6] Both models were implemented in Fortran and only differed in the way that the governing equations were solved. The simulations were run on a x86 (32-bit) architecture Pentium processor with a dual Intel Core Quad CPU 2.4 GHz processor and 3.0 GB memory.

\section{Zero-dimensional thermodynamic volume}

The performance of the recycling system is determined largely by the efficiency of the processes of charging and discharging. The vessels have been discretized by a zero-dimensional model, and the governing equations are as follows.

- Non-adiabatic charging:

$$
\begin{aligned}
\frac{d P}{d t}= & \dot{m}_{\mathrm{in}} \frac{R T}{V}\left(\gamma \frac{T_{\mathrm{in}}}{T}-\frac{v_{\mathrm{in}}^{2}}{2 c_{v} T}\right) \\
& -(\gamma-1) \frac{\alpha_{w} A_{w} T}{P V}\left(1-\frac{T_{w}}{T}\right) \\
\frac{d T}{d t}= & \dot{m}_{\mathrm{in}} \frac{R T^{2}}{P V}\left(\gamma \frac{T_{\mathrm{in}}}{T}-1-\frac{v_{\mathrm{in}}^{2}}{2 c_{v} T}\right) \\
& -(\gamma-1) \frac{\alpha_{w} A_{w} T^{2}}{P V}\left(1-\frac{T_{w}}{T}\right)
\end{aligned}
$$

- Non-adiabatic discharging:

$$
\begin{aligned}
\frac{d P}{d t}= & -\dot{m}_{\text {out }} \frac{R T}{V}\left(\gamma \frac{T_{\text {out }}}{T}-\frac{v_{\text {out }}^{2}}{2 c_{v} T}\right)-\frac{\alpha_{w} A_{w} T}{P V}\left(1-\frac{T_{w}}{T}\right) \\
\frac{d T}{d t}= & -\dot{m}_{\text {out }} \frac{R T^{2}}{P V}\left(\gamma \frac{T_{\text {out }}}{T}-1-\frac{v_{\text {out }}^{2}}{2 c_{v} T}\right) \\
& -(\gamma-1) \frac{\alpha_{w} A_{w} T^{2}}{P V}\left(1-\frac{T_{w}}{T}\right)
\end{aligned}
$$

where the suffix 'in' refers to the port where inflow occurs, and the suffix 'out' refers to the port where outflow occurs. It must be taken into account that the equations above are only valid under the assumption that a perfect mixing of the fluid to an equilibrium state occurs, so the use of a single pressure and temperature describe the state of the gas in the vessels.

\section{Mathematical model of the valve manifold}

The following discussion assumes that the spool valve only moves in the axial direction. Therefore, the deviation from the central position caused by unsteady transverse flow forces was not taken into account. The alignment of the spool valve with respect to the valve body is a basic factor in avoiding possible eccentricities which may cause a rotating movement of the spool valve, that may consequently lead to the generation of a moment with respect to its central axis.

The control volume depicted in Figure 2 describes the nature of $F_{s}$, which is represented by the static pressure force acting on the spool valve and the flow force $F_{f}$ yielded by the flow passage across the valve that originates a linear momentum change.

Therefore, based on the previous assumptions the dynamics of each spool valve is given by

$$
m_{s_{v_{i}}}\left(\ddot{z}_{v_{i}}+g\right)+c_{f} \dot{z}_{v_{i}}+k_{v_{i}}\left(z+z_{o}\right)_{v_{i}}=F_{f_{v_{i}}}+F_{S_{v_{i}}}
$$




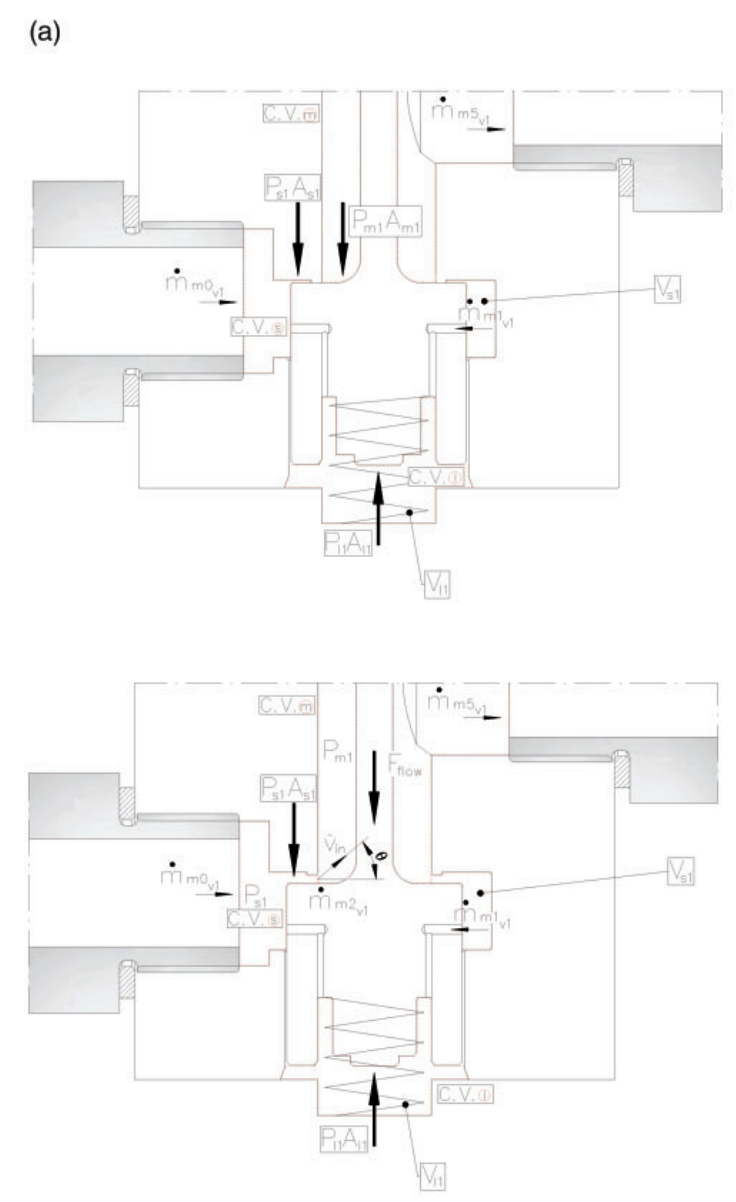

(b)

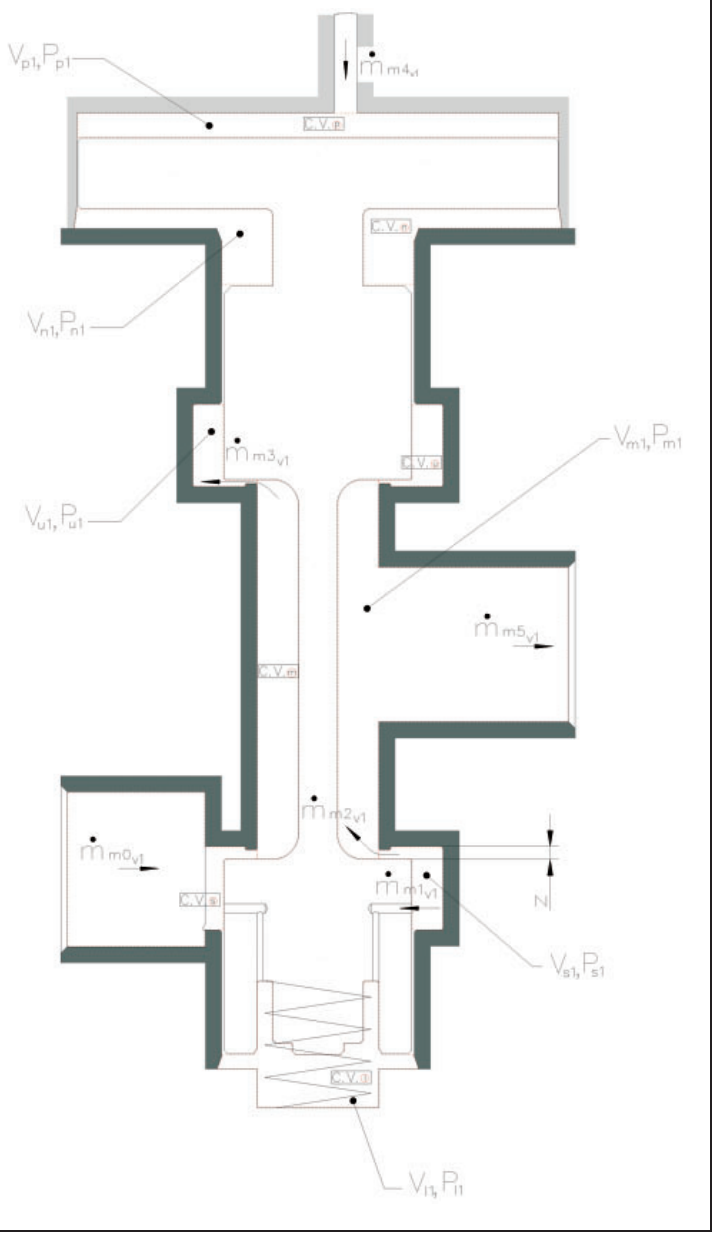

Figure 2. (a) Static and flow fluid forces acting on the spool valve lower packing before and after opening. (b) Schematic view of the main valve body and pilot ports of the pneumatic unit. [AQ7]

where $z$ is the instantaneous vertical displacement referenced from the seat, $k_{v_{i}}$ is the spring rate, $F_{S_{v_{i}}}$ and $F_{f_{v_{i}}}$ are the pressure forces acting on the entire control surface and the flow forces respectively, and $v_{i}$ is the index assigned to each spool valve.

The equation describing the dry friction force between the contacting surfaces can be mathematically represented as follows: ${ }^{15-19}$

$$
F_{c}=\left\{\begin{array}{lll}
F_{c_{n}} \operatorname{sgn}(\dot{z}) & & \text { if } \dot{z} \neq 0 \\
\xi & \text { if }|\xi|<\mathrm{F}_{\mathrm{c}_{0}} & \text { if } \dot{z}=0 \\
F_{c_{0}} \operatorname{sgn}(\xi) & \text { if }|\xi| \geqslant \mathrm{F}_{\mathrm{c}_{0}} & \text { if } \dot{z}=0
\end{array}\right.
$$

where $F_{c_{n}}$ is the nominal dry friction force on the spool valve, $F_{c_{0}}$ is the initial dry friction force on the spool valve, and $\xi=\sum_{i=1}^{n} P_{i} A_{i}-F_{f_{v_{i}}}-F_{s_{v_{i}}}$ represents the balance of forces acting on the spool valve body.

After applying the Navier-Stokes equations in vector form in the control volumes shown in Figure 2, the result will be as follows:

$$
\begin{aligned}
& m_{s_{v_{i}}} \ddot{z}_{v_{i}}+c_{f} \dot{z}_{v_{i}}+k_{v_{i}}\left(z+z_{o}\right)_{v_{i}} \\
& =\left(A_{p} P_{p}\right)_{v_{i}}+\left(A_{s} P_{s}\right)_{v_{i}}-\left(A_{u} P_{u}\right)_{v_{i}}-\left(A_{l} P_{l}\right)_{v_{i}}
\end{aligned}
$$

$$
\begin{aligned}
& -\left(A_{n} P_{n}\right)_{v_{i}}+m_{s_{i}} g-\frac{\partial}{\partial t}\left[\dot{m}\left(z+z_{o}\right)\right] \\
& -\dot{m}\left(v_{\text {out }}-v_{\text {in }}\right)
\end{aligned}
$$

The steady-state form of equation (6) is

$$
\begin{aligned}
k_{v_{i}}\left(z+z_{o}\right)_{v_{i}}= & \left(A_{p} P_{p}\right)_{v_{i}}+\left(A_{s} P_{s}\right)_{v_{i}}-\left(A_{u} P_{u}\right)_{v_{i}} \\
& -\left(A_{l} P_{l}\right)_{v_{i}}-\left(A_{n} P_{n}\right)_{v_{i}}+m_{s_{v_{i}}} g \\
& -\dot{m}\left(v_{\text {out }}-v_{\text {in }}\right)
\end{aligned}
$$

which can be manipulated in order to determine the minimum force required to shift the valve from the rest position,

$$
\begin{aligned}
& \left.A_{p} P_{p}\right)_{v_{i}} \geqslant k_{v_{i}}\left(z+z_{o}\right)_{v_{i}} \\
& \quad-\left(\left(A_{S} P_{S}\right)_{v_{i}}-\left(A_{u} P_{u}\right)_{v_{i}}-\left(A_{l} P_{l}\right)_{v_{i}}-\left(A_{n} P_{n}\right)_{v_{i}}+m_{v_{i}} g\right)
\end{aligned}
$$

The mass flow through the spool valve openings can be either subsonic or sonic depending on the pressure ratio between inlet and outlet pressure. 


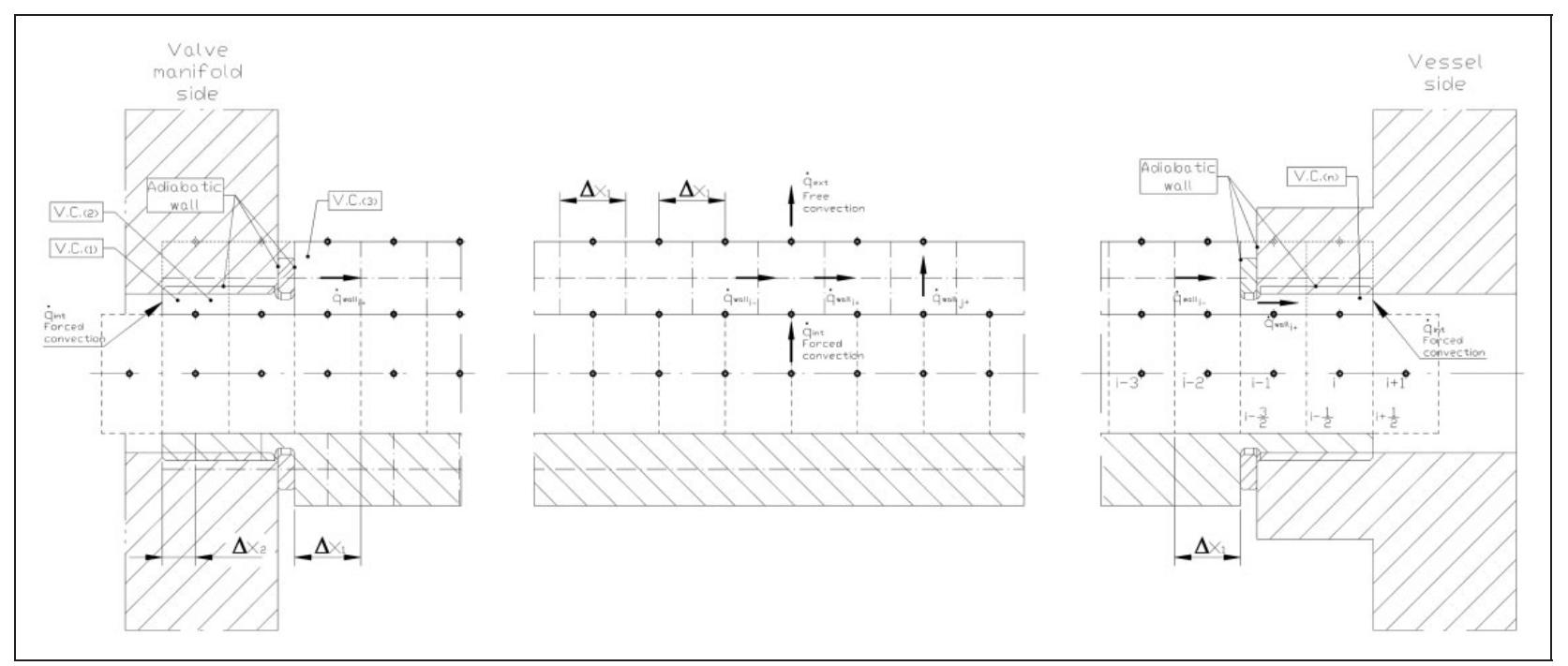

Figure 3. Computational grid along the axial direction of a non-tapered pipe for the HLL first-order scheme. [AQ9]

We, therefore, get

$$
\begin{aligned}
& \dot{m}_{m 2_{v_{i}}}=\left\{\begin{array}{cc}
C_{d_{2 v_{i}}} A_{0} \xi_{1} \frac{P_{(s), v_{i}}}{\sqrt{T_{(s), v_{i}}}} & \text { if } \frac{P_{(m), v_{i}}}{P_{(s), v_{i}}} \leqslant P_{c r} \\
\left\{\begin{array}{c}
C_{d_{2 v_{i}}} A_{0} \xi_{2} \frac{P_{(s), v_{i}}}{\sqrt{T_{(s), v_{i}}}}\left(\frac{P_{(m), v_{i}}}{P_{(s), v_{i}}}\right)^{1 / \gamma} \\
\times \sqrt{1-\left(\frac{P_{(m), v_{i}}}{P_{(s), v_{i}}}\right)^{(\gamma-1) / \gamma}}
\end{array}\right\} \text { if } \frac{P_{(m), v_{i}}}{P_{(s), v_{i}}}>P_{c r}
\end{array}\right.
\end{aligned}
$$

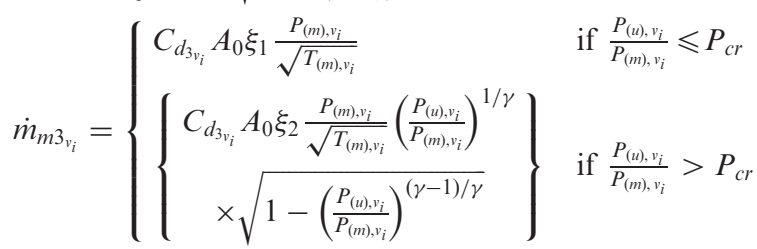

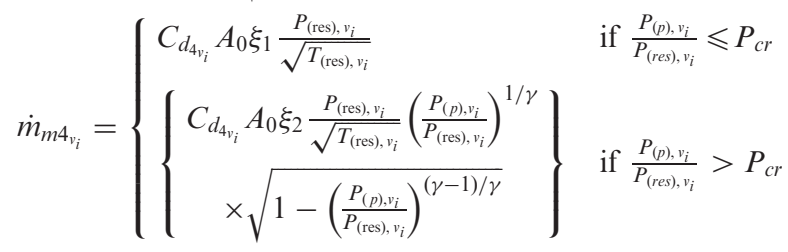

where $C_{d_{v_{j}}}$ is a non-dimensional discharge coefficient referring to the corresponding spool valve seat, and the subscript '(res)' refers to the reservoir that supplies air to the pilot port of the valve manifold. On the other hand the stagnation pressure and temperature of the fluid upstream and downstream of the restriction will alternately vary depending on the flow direction, and this applies equally to the downstream stagnation pressure. The following are constants that depend on the specific heat ratio of the given fluid:

$$
\begin{aligned}
\xi_{1} & =\sqrt{\frac{\gamma}{R}\left(\frac{2}{\gamma+1}\right)^{\frac{\gamma+1}{\gamma-1}}} ; \quad \xi_{2}=\sqrt{\frac{2 \gamma}{R(\gamma-1)}} ; \\
P_{\mathrm{cr}} & =\left(\frac{2}{\gamma+1}\right)^{\frac{\gamma}{\gamma-1}}
\end{aligned}
$$

The air flowing through the piloting channels, incorporated in the lower packing of the spool valves, is assumed to be laminar, ${ }^{20}$ and is determined by

$$
\dot{m}_{m 1_{v_{i}}}=\varrho_{\mathrm{av}} \frac{\pi d_{c}^{4}}{128 \mu_{\mathrm{av}}} \frac{\Delta P}{l_{c}}
$$

where $d_{c}$ and $l_{c}$ are the internal diameter and length of the piloting channels, $\mu_{a v}$ and $\varrho_{a v}$ are the average value of the dynamic viscosity and density of the fluid, and $\Delta P$ is the pressure drop between internal volumes.

The flow entering and exiting each valve port $\dot{m}_{0 / 5_{v_{i}}}$ will be calculated by the results obtained at the boundary conditions applied to the pipe ends.

[AQ8]On the other hand, the flow through any narrow annular clearance, where a sealing component is located, was ignored. This assumption was experimentally supported by ensuring that no internal leakage occurred when operating the unit.

\section{Boundary conditions}

The procedure used to determine the variable values at the boundaries has been based on solving the governing equations through a convergent nozzle. According to the discretization shown in Figure 3, the internal cavities of the valve manifold located immediately after the pipe ends were taken as small control volumes inside which the physical properties of the fluid could be determined under certain assumptions. Contrary to what occurs when considering the boundary conditions near a high-volume reservoir the speed of the fluid cannot be disregarded, and therefore the stagnation pressure will be influenced by the kinetic energy of the fluid at each specific control volume. The different cases that must be taken into account are as follows. 


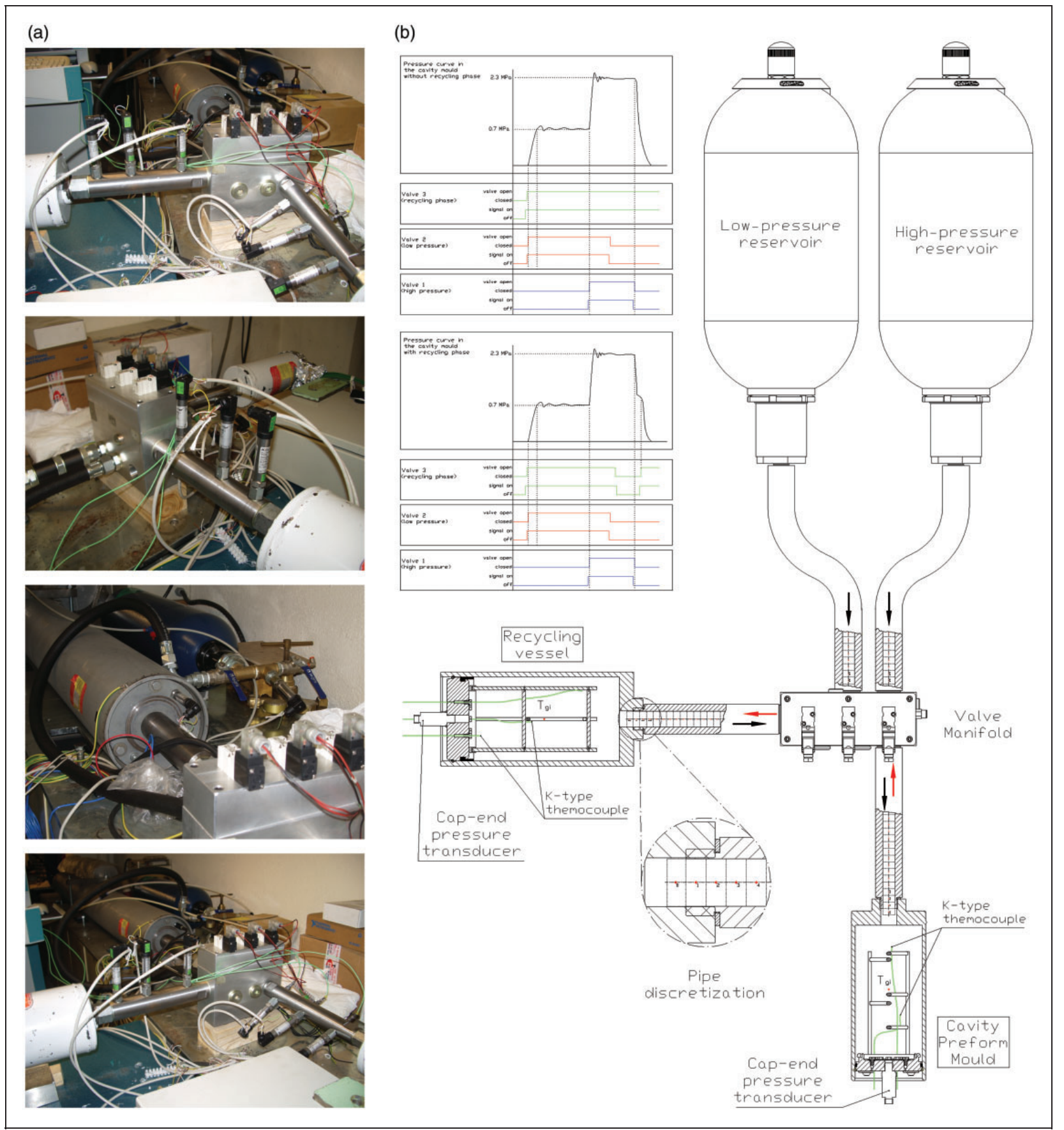

Figure 4. (a) Views of the air blowing experimental unit. (b) Schematic drawing of the experimental set-up. [AQ13]

1. Subsonic inflow

$$
\begin{aligned}
\left(\frac{d P}{d t}\right)_{p} \pm \varrho_{p} a_{p}\left(\frac{d u}{d t}\right)_{p}=(\gamma-1) \varrho\left(\dot{q}+u \frac{4 f}{D_{p}} \frac{u^{2}}{2} \frac{u}{|u|}\right) & \frac{P_{C}}{P_{T}}=\left(\frac{\varrho_{C}}{\varrho_{T}}\right)^{\gamma} \\
-\frac{a^{2} \varrho u}{A} \frac{\mathrm{d} A}{\mathrm{~d} x} \mp \frac{4 f}{D_{p}} \frac{\varrho a u^{2}}{2} \frac{u}{|u|}=0 & a_{C}^{2}=a_{T}^{2}+\frac{(\gamma-1)}{2} u_{T}^{2} \\
& P_{T}=P_{P}
\end{aligned}
$$$$
\varrho_{T} u_{T} \frac{A_{T}}{A_{P}}=\varrho_{P} u_{P}
$$$$
a_{C}^{2}=a_{P}^{2}+\frac{(\gamma-1)}{2} u_{P}^{2}
$$

2. Sonic inflow: in this case the equations governing the flow are the ones described above with the exception of the last equation, which will be replaced by the condition $a_{T}=u_{T}$. 


$$
\begin{aligned}
& \left(\frac{d P}{d t}\right) p \pm \varrho_{p} a_{p}\left(\frac{d u}{d t}\right)_{p}=(\gamma-1) \varrho\left(\dot{q}+u \frac{4 f}{D_{p}} \frac{u^{2}}{2} \frac{u}{|u|}\right) \\
& -\frac{a^{2} \varrho u}{A} \frac{d A}{d x} \mp \frac{4 f}{D_{p}} \frac{\varrho a u^{2}}{2} \frac{u}{|u|}=0 \\
& \varrho_{T} u_{T} \frac{A_{T}}{A_{P}}=\varrho_{P} u_{P} \\
& \left(\frac{d P}{d t}\right)_{p}-a_{P}^{2}\left(\frac{d \varrho}{d t}\right)_{P}=(\gamma-1) \varrho\left(\dot{q}+u \frac{4 f}{D_{p}} \frac{u^{2}}{2} \frac{u}{|u|}\right) \\
& a_{C}^{2}=a_{P}^{2}+\frac{(\gamma-1)}{2} u_{P}^{2} \\
& \frac{P_{P}}{P_{T}}=\left(\frac{\varrho_{P}}{\varrho_{T}}\right)^{\gamma} \\
& a_{P}^{2}+\frac{(\gamma-1)}{2} u_{P}^{2}=a_{T}^{2}+\frac{(\gamma-1)}{2} u_{T}^{2} \\
& P_{T}=P_{C}
\end{aligned}
$$

4. Sonic outflow: similarly to the sonic inflow the equations described above for the subsonic outflow can be used for the sonic case but with the exception of the last equations which must be substituted by $a_{T}=u_{T}$. [AQ10]

Therefore the state of gas at each boundary is obtained by solving the above equations coupled with the wave characteristics. ${ }^{21,22}$ To determine the boundary condition at the pipe end connected with the vessel, the state in the vessel at time $t+\Delta t$ is obtained explicitly from the state at time $t$.

\section{Experimental set-up}

The pneumatic configuration, previously detailed in Figure 1, will now be experimentally reproduced. The main purpose of the tests will be to assess the pressure and temperature variation at different locations of the single station air blowing unit. The high-pressure tank was supplied with a compressed air bottle charged up to 200 bar, while the low-pressure vessel was provided with compressed air from the existing line. The units were connected to the corresponding ports of the valve manifold, and similarly the output ports of the valve manifold were piped to the so-called cavity and recycling chambers. As mentioned in previous sections the static pressure inside the tanks was measured with pressure sensors (range: $0-10$ bar, accuracy $\pm 0.5 \%$ F.S.; range: $0-100$ bar, accuracy $\pm 2.5 \%$ F.S.), while the instantaneous gas temperature inside each volume was monitored with self-manufactured K-type thermocouples with an accuracy of $\pm 0.5^{\circ} \mathrm{C}$ over a measured range that goes from $25^{\circ} \mathrm{C}$ to $100^{\circ} \mathrm{C}$. Data-logging as well as the operating sequence of the pilot valves was monitored and programmed with Labview respectively. [AQ11] [AQ12]

The operating conditions of the single-station blowing unit were defined on the basis of the blowing stages applied by the PET manufacturers. The valve opening/closing sequencing arose from systematic testing. The initial trials helped to identify the limitations of the first prototypes. The maximum operating pressure under which the valve manifold was able to work varied between 20 and 30 bar respectively. Based on those results as well as on the limited size of the high-pressure tank the blowing test was set up in order to work up to a maximum operating pressure of 25 bar. [AQ14]

Based on the existing concept, the operating valve sequence plays a very important role during the first stage of the blowing process. The response time of the valves must be taken into account when defining the working cycle. The first experimental results helped to understand that the pressure in the cavity chamber usually exceeded the primary pressure when being supplied by the recovery tank. During the low-pressure blowing stage the pressure in the cavity chamber should not overtake the assigned low-pressure level, however, the response time of $V_{2}$ is not fast enough to prevent this type of functioning. Therefore it is necessary to energize $V_{2}$ before the pressure level in the cavity chamber reaches the requested value. Due to this fact, a pressure peak within the cavity vessel may be generated during the low-pressure blowing stage, which can be explained by the lack of a regulating device acting between the two vessels, so the internal geometry of the valve manifold as well as the existing pneumatic connections will constrain the efficiency of the system.

The situation described above only occurs if the pressure in the recovery tank at the end of the blowing cycle has reached a designated pressure level. Usually this level for the experimental tests under discussion is one and a half times or more the primary pressure ( $\left.P_{\text {low }}\right)$.

\section{Results and discussion}

Figures 5 illustrates the pressure characteristics based on the test set-ups highlighted in blue in Table 2. The results demonstrate a fairly clear correlation between the experimental and predicted results when using the MOC as well as the HLL solver in combination with the Fortran subroutine that solves the set of equations that allow measurement of the influence of the valve manifold. On the contrary, when employing nondimensional parameters $(C, b)$ to estimate the flow rate through the valve manifold ports, the result differs significantly from the empirical values. It must be noted that this approach was exclusively applied in combination with the MOC (MOC'). 


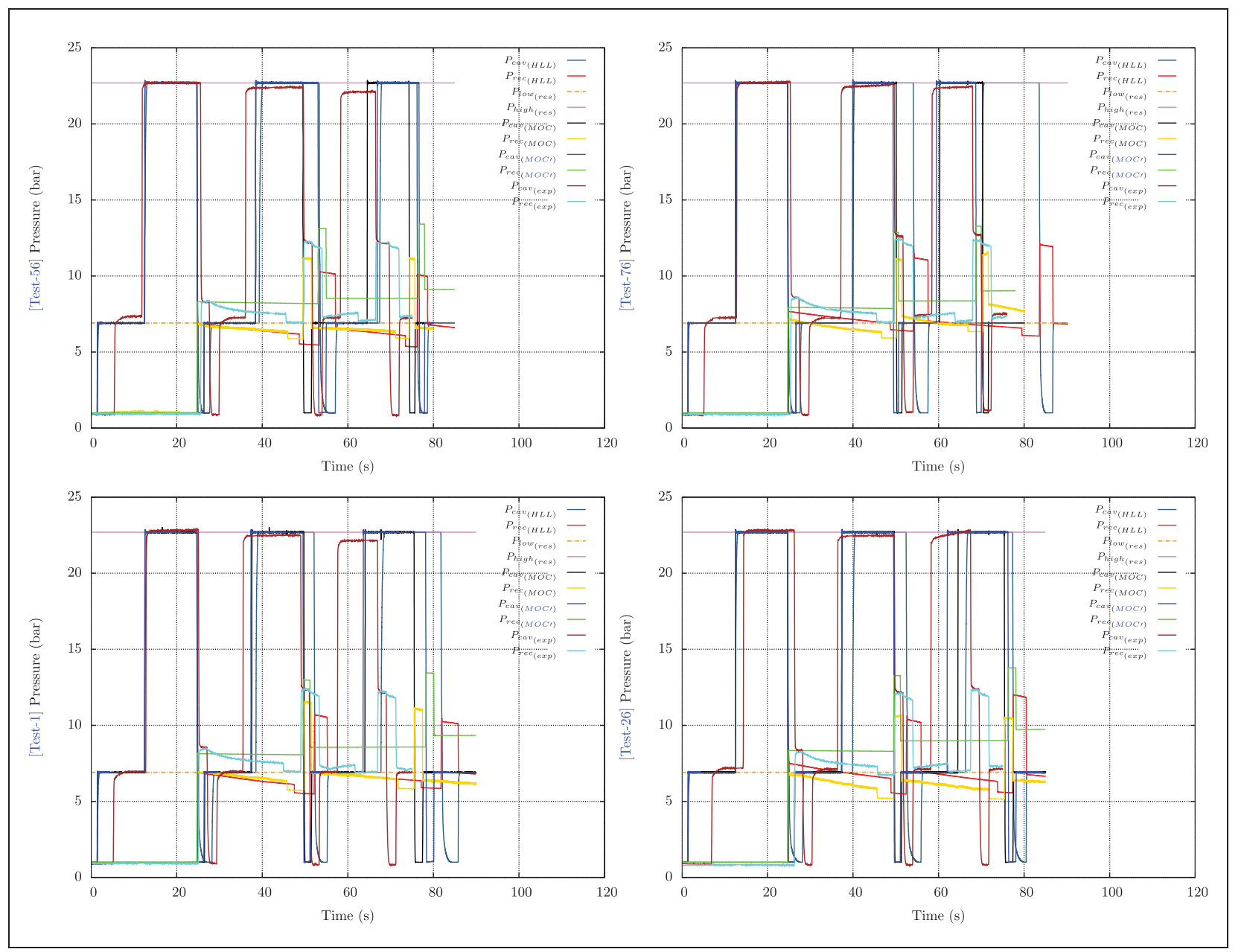

Figure 5. Pressure characteristics according to Test-I, Test-56, Test-26, and Test-76. HLL: subscript that refers to the HLL Riemann solver in combination with the valve manifold model; res: subscript that refers to the low- and high-pressure reservoirs respectively; MOC: subscript that refers to the MOC in combination with the valve manifold model; exp: subscript that refers to the experimental results; and MOCO: subscript that refers to the MOC in combination with the valve manifold represented by an equivalent elective orifice area.

On the other hand the progressive increase in pressure experienced within the recycling vessel, after feeding the cavity tank with recycled air, could not be reproduced with any of the solving methods. Even if the MOC provides a more realistic prediction, it is still below the maximum experimental recycling ratio that may be reached with the different pipe configurations. Moreover, this mathematical method faces some difficulties when referring to the stability of the flow at the boundaries. In this case the assumptions applied are not sufficiently consistent since the inner volume where the flow charge and discharge is quite small. On the contrary, the HLL Riemann solver shows a more accurate correlation which may be explained by the fact that the kinetic energy at the boundaries was not disregarded.

[AQ15]Additionally, when changing the state of valve $V_{3}$ at the end of the recycling phase, the remaining air in the cavity is exhausted to the atmosphere. The empirical results show a transition time which has not been reproduced by the simulation. As a matter of fact this delay was not intentionally generated during the experimental set-up. The reason behind this behaviour is based on the fact that the time required to equalize the pressure in the cavity and the recycling vessel was lower than the set-up time given to switch on valve $V_{3}$. The mathematical model, however, automatically alters the state of valve $V_{3}$ at the time that the pressures in the two tanks become the same. This discrepancy only affects the cycle time, not the recycling ratio.

All the illustrations indicate a promising correlation between the empirical and predicted values when observing the results obtained with the HLL solver model, however, the recycling rate is always below the experimental value, which is over 12 bar. In regards to this last aspect, it should be pointed out that despite the fact that the MOC shows closer correspondence with the empirical results, those are still below the previously mentioned pressure level.

Under the assumption that the pneumatic circuit shown in Figure 4 is part of a PET bottle stretch blow moulding machine with a production rate of 20,000 bottles per hour (this value being a variable 


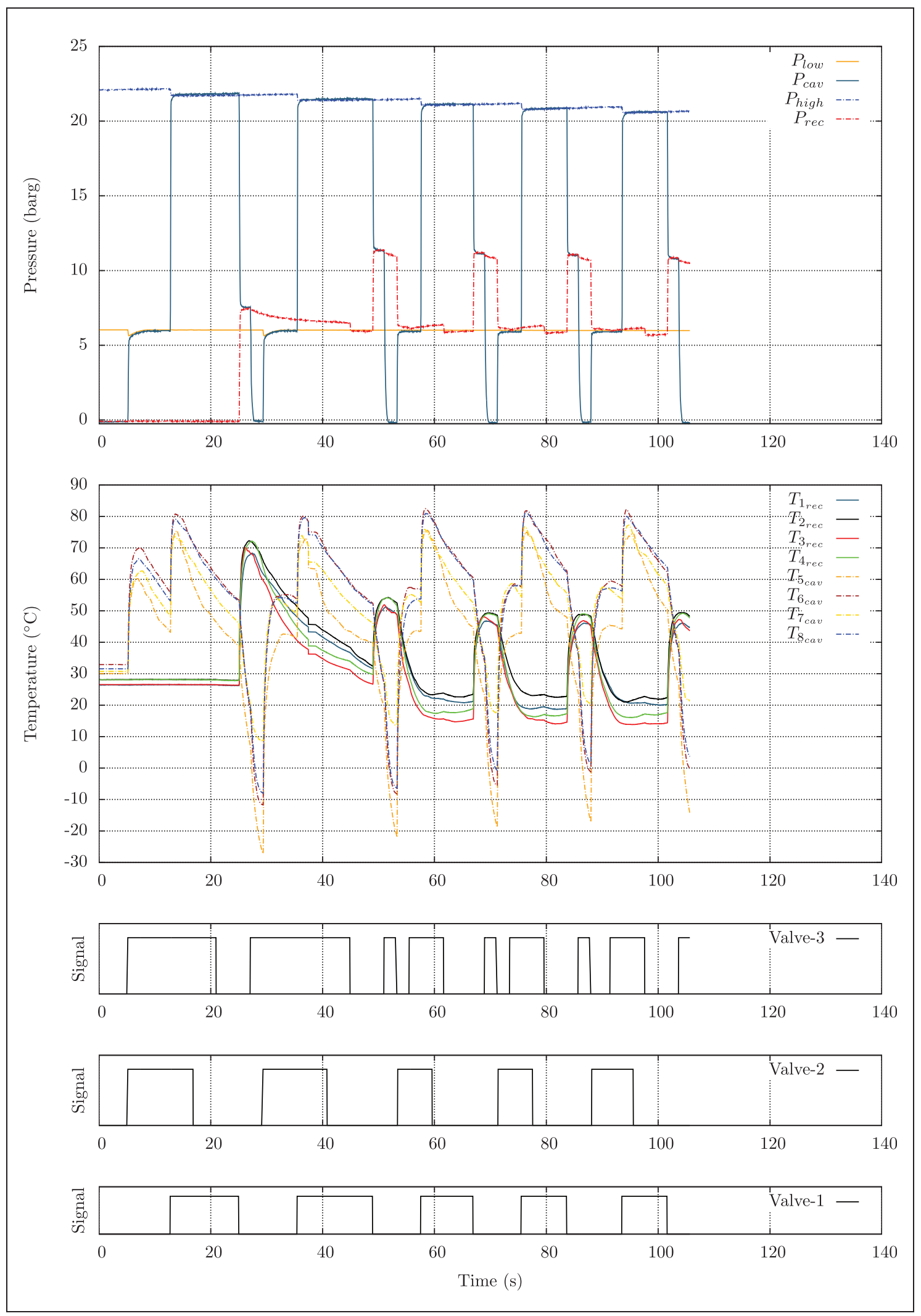

Figure 6. Experimental results according to set-up Test-I (refer to Table 2).

which depends on the blowing machine concept and the volume of the item to be produced), a pre-blowing phase of 7 bar and a final blowing phase of 23 bar, it may be determined that the maximum theoretical energy consumption is $23 \cdot 10^{2} \frac{\mathrm{N}}{\mathrm{m}^{2}} \cdot \frac{0.0015 \cdot 20,000}{3600} \frac{\mathrm{m}^{3}}{\mathrm{~s}}=19.2$ $\mathrm{kW}$ (note that the volume of the mould cavity under study is $1.5 \mathrm{dm}^{3}$ ). The experimental results (refer to Figure 5) demonstrate that up to a minimum pressure 
Table I. Valve manifold specifications (refer to Figure I). [AQ28]

\begin{tabular}{|c|c|c|}
\hline \multirow{2}{*}{$\begin{array}{l}\text { Type } \\
\text { Fluid }\end{array}$} & \multicolumn{2}{|c|}{$\begin{array}{l}\text { Pilot-operated } \\
\text { poppet valve }\end{array}$} \\
\hline & \multicolumn{2}{|l|}{ Air } \\
\hline Operating pressure range ( $\mathrm{MPa})$ & \multicolumn{2}{|c|}{$0.6 \sim 0.7$} \\
\hline Maximum working pressure ( $\mathrm{MPa})$ & \multicolumn{2}{|c|}{2.5} \\
\hline \multirow{5}{*}{ Sonic conductance $\left(\frac{\mathrm{dm}^{3}}{\mathrm{~s} \cdot \mathrm{bar}}\right)$} & Path I-3 & 10.3 \\
\hline & Path 2-3 & 15.0 \\
\hline & Path 3-4 & 8.3 \\
\hline & Path 4-3 & 8.3 \\
\hline & Path 3-9 & 8.4 \\
\hline Fluid temperature $\left({ }^{\circ} \mathrm{C}\right)$ & \multicolumn{2}{|c|}{$5 \sim 50$} \\
\hline Ambient temperature $\left({ }^{\circ} \mathrm{C}\right)$ & \multicolumn{2}{|c|}{$5 \sim 50$} \\
\hline Body material & \multicolumn{2}{|c|}{ Aluminium } \\
\hline Seal material & \multicolumn{2}{|c|}{ NBR } \\
\hline Enclosure & \multicolumn{2}{|c|}{ Dust-proof } \\
\hline Mounting orientation & \multicolumn{2}{|c|}{ Vertical } \\
\hline Voltage & \multicolumn{2}{|c|}{ DC24V } \\
\hline
\end{tabular}

Table 2. Matrix of test set-ups (dimensions in $\mathrm{mm}$ ).

\begin{tabular}{lllll}
\hline & & $\begin{array}{l}\mathrm{L}_{\text {cav }}=300 \\
\mathrm{D}_{\text {pcav1 }} / \mathrm{D}_{\text {pcav2 }} \\
\varnothing|8-\varnothing| 8\end{array}$ & $\begin{array}{l}\mathrm{L}_{\text {cav }}=100 \\
\mathrm{D}_{\text {pcav1 }} / \mathrm{D}_{\text {pcav2 }} \\
\varnothing|8-\varnothing| 8\end{array}$ \\
\hline $\mathrm{L}_{\text {rec }}=260$ & $\mathrm{D}_{\text {prec1 }} / \mathrm{D}_{\text {prec2 }}$ & $\varnothing 23.5-\varnothing 23.5$ & Test-I & Test-6 \\
& & $\varnothing 23.5-\varnothing \mid 8$ & Test-2। & Test-26 \\
$\mathrm{L}_{\text {rec }}=100$ & $\mathrm{D}_{\text {prec1 }} / \mathrm{D}_{\text {prec2 }}$ & $\varnothing 23.5-\varnothing 23.5$ & Test-5। & Test-56 \\
& & $\varnothing 23.5-\varnothing \mid 8$ & Test-7| & Test-76 \\
\hline
\end{tabular}

Note: $D_{p_{\text {cav }}}$ and $D_{p_{\text {rec }}}$ refer to the pipe diameters connected to the valve manifold, and $D_{p_{\text {cav }}}$ and $D_{p_{\text {rec }}}$ refer to the pipe diameters connected to the cavity and recycling chambers respectively. [AQ29] of 12 bar could be ensured at the end of the recycling phase, which is equivalent to $10 \mathrm{~kW}$. Hence, the efficiency of the blowing machine is as follows:

$$
\eta=\frac{\text { Energy recovered }}{\text { Energy supplied }}=\frac{10}{19.2}=0.52
$$

However, the main drawback of this proposal is that the only way to increase the recovery rate is to provide a higher pressure level during the secondary phase or, conversely, delay the recovery process until the specific pressure level in the recovery tank is reached. This last point can only be accomplished after a certain number of operating cycles, in other words, one recovery cycle will not be enough to reach a certain pressure level and therefore the pneumatic system will become less efficient.

\section{Conclusion}

The primary intent of this work has been to demonstrate the difficulties of improving the efficiency of a standard high-pressure pneumatic application. Specifically, attention has been focused on analysing an air-blowing PET bottle single-station unit. In pursuing this goal, it has been necessary to apply various mathematical methods in order to learn about the particular aspects of the unsteady flow through the pipes, develop a special valve manifold and later manufacturing, and finally, reproduce the industrial operating conditions, taking into account the existing constraints of our test facility, and monitor the pressure and temperature characteristics under different configurations.

[AQ16]The experimental set-up phase was proved to be capable of reproducing the industrial conditions normally used by PET bottle manufacturers. The major drawback, associated with the maximum pressure level that could be ensured during the high-pressure air

Table 3. Comparison of maximum recycling pressure rate according to Test-I, Test-56, Test-26 and Test-76.

\begin{tabular}{|c|c|c|c|c|c|c|}
\hline \multirow{3}{*}{$\begin{array}{l}\text { Recycling pressure rate at } \\
\text { different operating cycles } \\
\text { (bar) }\end{array}$} & \multicolumn{6}{|c|}{ Test set-up } \\
\hline & \multicolumn{3}{|l|}{ Test-I } & \multicolumn{3}{|l|}{ Test-56 } \\
\hline & Ist cycle & 2nd cycle & 3rd cycle & Ist cycle & 2nd cycle & 3rd cycle \\
\hline Experimental & 12.37 & 12.23 & 12.05 & 12.27 & 12.20 & 12.10 \\
\hline HLL solver & 10.78 & 10.31 & 10.55 & 10.32 & 10.19 & 10.48 \\
\hline MOC & 11.67 & 11.22 & 11.04 & $\mid 1.31$ & 11.28 & 11.29 \\
\hline$\%\left[\frac{(\text { HLL-Exp) }}{\operatorname{Exp}}\right]$ & 14.75 & 18.62 & 14.22 & 18.9 & 19.72 & 15.46 \\
\hline$\%\left[\frac{(M O C-\operatorname{Exp})}{\operatorname{Exp}}\right]$ & 6.00 & 9.00 & 9.15 & 8.49 & 8.16 & 7.17 \\
\hline
\end{tabular}

\begin{tabular}{|c|c|c|c|c|c|c|}
\hline \multirow{3}{*}{$\begin{array}{l}\text { Recycling pressure rate at } \\
\text { different operating cycles } \\
\text { (bar) }\end{array}$} & \multicolumn{6}{|c|}{ Test set-up } \\
\hline & \multicolumn{3}{|l|}{ Test-26 } & \multicolumn{3}{|l|}{ Test-76 } \\
\hline & Ist cycle & 2nd cycle & 3rd cycle & Ist cycle & 2nd cycle & 3 rd cycle \\
\hline Experimental & 12.10 & 12.29 & 12.52 & 12.39 & 12.35 & 12.24 \\
\hline HLL solver & 10.45 & 12.12 & 10.48 & 11.26 & 12.16 & 11.14 \\
\hline
\end{tabular}


Table 3. Continued

\begin{tabular}{|c|c|c|c|c|c|c|}
\hline \multirow{3}{*}{$\begin{array}{l}\text { Recycling pressure rate at } \\
\text { different operating cycles } \\
\text { (bar) }\end{array}$} & \multicolumn{6}{|c|}{ Test set-up } \\
\hline & \multicolumn{3}{|l|}{ Test-26 } & \multicolumn{3}{|l|}{ Test-76 } \\
\hline & Ist cycle & 2nd cycle & 3rd cycle & Ist cycle & 2nd cycle & 3rd cycle \\
\hline MOC & 10.72 & 10.63 & 10.72 & 11.24 & 11.69 & 12.29 \\
\hline$\%\left[\frac{(H L L-\operatorname{Exp})}{\operatorname{Exp}}\right]$ & 15.82 & 1.40 & 19.47 & 10.04 & 1.56 & 9.87 \\
\hline$\%\left[\frac{(\text { MOC-Exp })}{\operatorname{Exp}}\right]$ & 12.87 & 15.62 & 16.79 & 10.23 & 5.65 & $-0.4 I$ \\
\hline
\end{tabular}

blowing stage, was not an obstacle to validate the functionality of the pneumatic system. The pressure history during the air-blowing experiments exhibited a clear dependence on the heat transfer through the vessel and pipe walls. As demonstrated, the amount of recycled air supplied to the cavity vessel during the low-pressure air blowing phase allowed avoiding the use of a low-pressure compressor. It must be noticed that the air recovery ratio could feed the air blowing line during the low-pressure stage after the first operating cycle. This solution, therefore, ensures a high efficiency rate which allowed up to $52 \%$ of air recovery; however, it must be kept in mind that in the case of increasing the cavity volume (bottle) the recycling line must also experience a percentage increase in order to balance the pressure/volume rate between both. The design of a valve manifold including an air recovery port could be successfully accomplished and revealed the strong impact on the pressure characteristics over a certain number of operating cycles. From this last point, it can be concluded that the manifold could not be considered as a flow restriction with an equivalent orifice area since the internal design plays a very important role in the amount of air that can be recovered. The numerical models were demonstrated to be in agreement with the experimental data, especially when coupling the unsteady fluid flow governing equations at the pipes with the set of equations that rule the pressure and temperature characteristics within the valve manifold.

\section{Acknowledgements}

This research was supported by Labson-UPC (Research Group 2014 SGR 575 Generalitat de Catalunya). We would like to thank Professors Gustavo Raush Alviach and Francisco Javier Freire Venegas, who provided insight and expertise that greatly assisted the research, as well as the advice given during the revisions of this paper.

\section{Declaration of Conflicting Interests}

The author(s) declared no potential conflicts of interest with respect to the research, authorship, and/or publication of this article.

\section{Funding}

This research received no specific grant from any funding agency in the public, commercial or not-for-profit sectors. [AQ17]

\section{References [AQ18] [AQ19]}

1. Fukushima H, Handa T and Kodama K. Process for the production of blow molded articles accompanied with the recovery of a blowing gas. Patent 4394333, 1981.

2. Wayne C. Recycling of blow air. Patent 4488863, 1984.

3. Weiss R. Multiple utilization of working air. Patent 5585066, 1994.

4. Weiss R. Multiple utilization of blow-mold air. Patent 5648026, 1994.

5. Siegrist R and Stillhard B. Stretch blow forming method and blow forming press. Patent WO1996025285 A1, 1991.

6. Ikeda M. Air operation method and apparatus of various drive devices of stretch blow molded part. Japanese Patent JPH0985812, Japan, 1995.

7. Hirokazu Y. Patent JPH05309726 (A), 1993. [AQ20].

8. Jover D and Storione S. Container blowing device. European Patent WO03/009993, 2003.

9. Trujillo J. Energy efficiency of high pressure pneumatic systems. Doctoral dissertation, 2015. [AQ21].

10. Shapiro A. The dynamics and thermodynamics of compressible fluid flow. vol. I. [AQ22]The Ronald Press Company, 1953.

11. Shapiro A. The dynamics and thermodynamics of compressible fluid flow. vol. II. [AQ23]The Ronald Press Company, 1954.

12. Toro E. Riemann solvers and numerical methods for fluid dynamics: A practical introduction. Berlin: SpringerVerlag, 2009.

13. Toro E. Shock-capturing methods for free-surface shallow flows. New York, NY: Wiley and Sons Ltd, 2001.

14. Toro E. NUMERICA: A library of source codes for teaching, research and applications. HYPER-EUL. Methods for the Euler equations. New York, NY: Wiley and Sons Ltd, 1999.

15. Andrighetto P, Valdiero A and Carlotto L. Study of the friction behavior in industrial pneumatic actuators. In: ABCM symposium series in mechatronics, 2006. [AQ24].

16. Berger E. Friction modelling for dynamic system simulation. American Society of Mechanical Engineers 2002 [AQ25].

17. Gordić D, Babić M and Jovicić N. Modelling of spool position feedback servovalves. Int J Flu Pow 2004.

18. Radcliffe C and Southward S. A property of stick-slip friction models which promotes limit cycle generation. In: American control conference, 1990.

19. Southward S, Radcliffe C and MacCluer C. Robust non-linear stick-slip friction compensation. J Dyn Syst Measure Contr 1991. 
20. Andersen B. The analysis and design of pneumatic systems. New York, NY: John Wiley and Sons, Inc, 1967.

21. López E. Methodologies for the numerical simulation of fluid flow in internal combustion engines. Doctoral Dissertation, 2009 [AQ26].

22. López E and Nigro N. Validation of a $0 D / 1 D$ computational code for the design of several kind of internal combustion engines. Investigación aplicada latinoamericana 2010 [AQ27].

\section{Appendix}

\section{Notation}

Roman symbols

$\alpha$

$\ddot{z}$

$\dot{q}$

$\dot{z}$

$\dot{m}$

$\eta$

$\gamma$

$\mu$

$\mu$

$\varrho$

A

$a$

$A_{0}$

$b$

C

C

$C_{d}$

$c_{f}$
Heat transfer coefficient $\left[\frac{\mathrm{W}}{\mathrm{m}^{\circ} \mathrm{C}}\right]$

Spool valve acceleration $\left[\frac{\mathrm{m}}{\mathrm{s}^{2}}\right]$

Rate of heat transfer per unit mass of fluid and per unit time $\left[\frac{\mathrm{W}}{\mathrm{kg}}\right]$

Spool valve velocity $\left[\frac{\mathrm{m}}{\mathrm{s}}\right]$

Mass flow rate $\left[\frac{\mathrm{kg}}{\mathrm{s}}\right]$

System efficiency

Ratio of specific heat [-]

Fluid dynamic viscosity $\left[\frac{\mathrm{kg}}{\mathrm{ms}}\right]$

Mass density $\left[\frac{\mathrm{kg}}{\mathrm{m}^{3}}\right]$

Area $\left[\mathrm{m}^{2}\right]$

Velocity of sound $\left[\frac{\mathrm{m}}{\mathrm{s}}\right]$

Orifice area $\left[\mathrm{m}^{2}\right]$

Critical pressure ratio [-]

Fluid state at the chamber

Sonic conductance of a component

under test $\left[\frac{\mathrm{m}^{4} \cdot \mathrm{s}}{\mathrm{kg}}\right]$

Discharge coefficient [-]

Viscous friction damping coefficient for moving parts in the valve $\left[\frac{\mathrm{kg}}{\mathrm{s}}\right]$
Specific heat at constant pressure $\left[\frac{\mathrm{J}}{\mathrm{kg}^{\circ} \mathrm{K}}\right]$

Specific heat at constant volume $\left[\frac{\mathrm{J}}{\mathrm{kg}^{\circ} \mathrm{K}}\right]$

$D_{p} \quad$ Pipe diameter [m]

$e_{0} \quad$ Stagnation internal energy $\left[\frac{\mathrm{J}}{\mathrm{kg}}\right]$

$f \quad$ Friction coefficient in the pipe [-]

$F_{c} \quad$ Friction force on the spool valve [N]

$F_{f} \quad$ Flow forces acting on the spool

valve $[\mathrm{N}]$

$F_{S} \quad$ Static forces acting on the spool

valve $[\mathrm{N}]$

Gravity acceleration $\left[\frac{\mathrm{m}}{\mathrm{s}^{2}}\right]$

$g$

in

Entry fluid flow to the spool valve

control volume

$k$

$m$

$m_{S}$

out

Spring constant $\left[\frac{\mathrm{N}}{\mathrm{m}}\right]$

Fluid mass [kg]

Mass of moving parts in the valve manifold $[\mathrm{kg}]$

Exit fluid flow from the spool valve control volume

Fluid pressure [Pa]

$P$
$P$

$P_{\text {cr }}$

Fluid state at the pipe end

Critical pressure

Gas constant $\left[287 \frac{\mathrm{J}}{\mathrm{kg}^{\circ} \mathrm{K}}\right]$

Fluid state at the nozzle throat

Gas temperature $\left[{ }^{\circ} \mathrm{K}\right]$

Time [s]

Wall temperature $\left[{ }^{\circ} \mathrm{K}\right.$ ]

Gas velocity in $\mathrm{x}$-direction $\left[\frac{\mathrm{m}}{\mathrm{s}}\right]$

Gas volume $\left[\mathrm{m}^{3}\right]$

Velocity of jet at vena contracta $\left[\frac{\mathrm{m}}{\mathrm{s}}\right]$

Index referring to each spool valve of the valve manifold

Inner surface of vessel

Cartesian coordinate [m]

Spool valve displacement [m]

Initial displacement of spool valve [m] 